\title{
Predictors for hemodynamic improvement with temporary pacing after pediatric cardiac surgery
}

\author{
Scott R. Ceresnak, MD, ${ }^{\mathrm{a}}$ Robert H. Pass, MD, ${ }^{\mathrm{b}}$ Thomas J. Starc, MD, ${ }^{\mathrm{a}}$ Allan J. Hordof, MD, ${ }^{\mathrm{a}}$ \\ William J. Bonney, MD, ${ }^{a}$ Ralph S. Mosca, MD, a and Leonardo Liberman, MD ${ }^{\mathrm{a}}$
}

\begin{abstract}
Objectives: Temporary epicardial pacing wires are commonly placed during pediatric cardiac surgery. Data are sparse on postoperative pacing in this population. The objective of this study was to determine the frequency of use and identify predictors for the use of temporary epicardial pacing wires.
\end{abstract}

Methods: Perioperative data were prospectively collected on all patients who underwent cardiac surgery at our institution $(\mathrm{n}=162)$.

Results: A total of 117 (72\%) patients had temporary epicardial pacing wires placed. Postoperatively, 23 (20\%) of 117 patients had hemodynamic improvement with the use of temporary epicardial pacing wires. Indications for pacing were slow junctional rhythm $(11 / 23[48 \%])$, junctional ectopic tachycardia $(7 / 23[31 \%])$, pace termination of supraventricular tachycardia $(3 / 23[13 \%])$ and atrial flutter $(1 / 23[4 \%])$, and complete heart block $(1 / 23$ $[4 \%])$. By using univariate analysis, single-ventricle anatomy, heterotaxy, the Fontan procedure, use of circulatory arrest, intraoperative arrhythmia, pacing in the operating room, and use of vasoactive medications were predictors for hemodynamic improvement with the use of temporary epicardial pacing wires $(P<.05)$. On multivariate analysis, the Fontan procedure, circulatory arrest, and intraoperative arrhythmias were independent predictors $(P<.01)$. When excluding all patients with any of these 3 risk factors, only $2 \%$ were paced. Patients with clinically significant pacing had longer chest tube drainage $(P<.01)$ and intensive care unit length of stay $(P<.01)$. There were no complications associated with temporary epicardial pacing wires.

Conclusions: The Fontan procedure, use of circulatory arrest, and intraoperative arrhythmias were associated with hemodynamic improvement with postoperative pacing and might represent indications for empiric intraoperative placement of temporary epicardial pacing wires. Patients without these risk factors were less likely to require pacing. Temporary epicardial pacing wires were safe and useful in the management of arrhythmias after pediatric cardiac surgery. (J Thorac Cardiovasc Surg 2011;141:183-7)

Temporary epicardial pacing wires are frequently placed during pediatric cardiac surgery and are often used in the diagnosis and management of postoperative rhythm disturbances. $^{1-4}$ Temporary epicardial pacing wires have been used routinely for decades; however, there has been recent literature suggesting that there is no need for routine placement of temporary leads during cardiac surgery in both the adult and pediatric populations. ${ }^{5,6}$ Arguments against the routine placement of temporary epicardial pacing wires primarily involve the risks associated with their use and removal. Complications, such as infection, bleeding, retained foreign bodies, ventricular fibrillation, and pericardial tamponade, have been reported. ${ }^{2,7-10}$ There is minimal literature, however, on the utility, predictors for

\footnotetext{
From the Divisions of Pediatric Cardiology and Cardiothoracic Surgery, ${ }^{\mathrm{a}}$ New York Presbyterian Hospital-Columbia, New York, NY, and the Division of Pediatric Cardiology, ${ }^{\mathrm{b}}$ Children's Hospital at Montefiore, Bronx, NY.

Disclosures: Authors have nothing to disclose with regard to commercial support

Received for publication June 25, 2009; revisions received Dec 23, 2009; accepted for publication March 16, 2010; available ahead of print July 26, 2010.

Address for reprints: Scott R. Ceresnak, MD, Division of Pediatric Cardiology, The Children's Hospital at Montefiore, 3415 Bainbridge Ave, Bronx, NY 10467 (E-mail: ceresnak@yahoo.com).

$0022-5223 / \$ 36.00$

Copyright (c) 2011 by The American Association for Thoracic Surgery doi:10.1016/j.jtcvs.2010.03.048
}

use, and complications associated with temporary epicardial pacing wires in children.

The aims of this study were to determine the frequency of use of temporary epicardial pacing wires, identify predictors for hemodynamic improvement with temporary pacing, and examine the complications associated with the use and removal of temporary epicardial pacing wires in pediatric patients undergoing cardiac surgery.

\section{MATERIALS AND METHODS}

After institutional review board approval was obtained, a prospective assessment of our institutional experience with the use of temporary epicardial pacing wires from June through November 2007 was performed. All patients undergoing surgical repair for congenital heart disease at the Morgan Stanley Children's Hospital of New York by any of 3 cardiothoracic surgeons were included. The exclusion criteria were patients undergoing isolated surgical ligation of a patent ductus arteriosus and patients undergoing implantation of a permanent pacemaker. Temporary epicardial pacing wires were placed intraoperatively at the discretion of the surgeon.

\section{Data Collection}

Data were collected preoperatively, intraoperatively, and postoperatively on all patients. Preoperative data included age, height, weight, cardiac lesion, medications, history of arrhythmias, additional medical problems cardiac function on echocardiographic analysis, prior operations, prior catheterizations, and baseline electrocardiographic findings (sinus or nonsinus 


\section{Abbreviations and Acronyms \\ $\mathrm{CICU}=$ cardiac intensive care unit \\ $\mathrm{OR}=$ odds ratio}

rhythm; PR, QRS, and QT intervals; and QRS axis). Intraoperative data included procedure performed, surgeon, bypass time, crossclamp time, circulatory arrest time, intraoperative arrhythmias, need for pacing, use of antiarrhythmic medications, placement of atrial or ventricular wires (unipolar or bipolar), placement of chest tubes, and cardiac function on transesophageal or epicardial echocardiographic analysis at the conclusion of surgical intervention. Postoperative data included initial blood pressure, oxygen saturation, lactate levels, and arterial blood gases on admission to the cardiac intensive care unit (CICU); initial postoperative electrocardiographic findings (sinus or nonsinus rhythm; PR, QRS, and QT intervals; and QRS axis); use of inotropes, length of intubation; length of chest tube requirement; daily review of telemetry; occurrence of arrhythmias, use of antiarrhythmic medications; electrolyte abnormalities at the time of arrhythmia; use of pacing wires for pacing or for atrial electrograms; hemodynamic changes associated with pacing; complications from pacing wire removal; number of days with pacing wires, CICU length of stay; and hospital length of stay. Patients' charts and telemetry were reviewed on a daily basis for each patient for the entire duration of the hospital course. The decision to use the temporary epicardial pacing wires was made by the CICU or cardiology attending physician.

\section{Definition of Clinically Significant Pacing}

Pacing was considered to be clinically significant or beneficial if, in the absence of any other intervention at the time pacing was initiated, pacing produced an increase in blood pressure of at least $10 \mathrm{~mm} \mathrm{Hg}$ or there was an improvement in cardiac output measured by resolution of metabolic acidosis, improved urinary output, or both.

\section{Statistical Analysis}

Data were analyzed with STATA 9.2 statistical software (StataCorp, College Station, Tex). Categorical and dichotomous variables were expressed as percentages, and continuous variables were expressed as means \pm standard deviations. For univariate analysis, $\chi^{2}$ or Fisher's exact tests were used for dichotomous variables, and Student's $t$ test was used for continuous data. The variables that were significant with univariate analysis were used in a logistic regression model for multivariate analysis.

\section{RESULTS}

There were 162 patients who met the inclusion criteria and were enrolled in the study (Table 1). Of those, 117 $(72 \%)$ had temporary epicardial pacing wires placed. There were 84 patients with atrial wires, 9 patients with ventricular wires, and 24 patients with both atrial and ventricular wires. A total of $29(29 / 117$ [25\%]) patients had the temporary wires used for diagnostic purposes to evaluate the underlying rhythm or to assist in the diagnosis of an arrhythmia.

\section{Pacing}

Of the 117 patients who underwent placement of temporary epicardial pacing wires, $35(30 \%)$ were paced. However, only $23(20 \%)$ were noted to have significant clinical improvement with pacing. The indications for pac- ing in the 12 patients who did not have significant improvement from pacing were as follows: sinus bradycardia $(\mathrm{n}=5)$, slow junctional rhythm $(\mathrm{n}=4)$, supraventricular tachycardia $(n=2)$, and use of the temporary wires for an electrophysiologic study $(\mathrm{n}=1)$. Of all the patients who were paced, $66 \%$ (23/35) had hemodynamic improvement with pacing. The 23 patients with clinical improvement with pacing were the subjects of our analysis. Preoperative, intraoperative, and postoperative data comparing these patients with the remainder of the population are listed in Table 2. Indications for pacing in this group were as follows: slow junctional rhythm (11/23 [48\%]), junctional ectopic tachycardia (7/23 [30\%]), supraventricular tachycardia $(3 / 23[13 \%])$, complete heart block $(1 / 23[4 \%])$, and atrial flutter (1/23 [4\%]). Four (17\%) patients had the wires used for acute tachycardia as opposed to more prolonged pacing. Of these 23 patients, 22 underwent atrial pacing, and 1 underwent ventricular pacing. Pacing was initiated in $20(87 \%)$ of the 23 patients within the first 24 hours postoperatively. The remaining 3 patients were paced on postoperative days 2,3 , and 7 , respectively, and all were paced for termination of supraventricular tachycardia. None of the patients who underwent surgical intervention during the study period $(n=162)$ required placement of a temporary pacing lead after leaving the operating room. The mean duration of pacing was 2.7 days $(95 \%$ confidence interval, 1.8-3.6 days). None of the patients were paced after postoperative day 9. One patient required placement of a permanent pacemaker because of persistent surgical complete heart block.

There were 4 patients who did not have temporary epicardial pacing wires who would have been paced had pacing wires been placed at the time of the operation. All 4 patients would have been paced within the first 24 postoperative hours. One patient was a 6-month-old with complex single-ventricle anatomy who underwent a bidirectional Glenn procedure. The patient was noted to have a cardiac arrest after ventricular fibrillation, and after successful defibrillation, this patient experienced a prolonged slow ventricular escape rhythm and would have been paced with both atrial and ventricular pacing wires after defibrillation. The second patient was a 3-year-old who underwent repair of a doublechamber right ventricle, ventricular septal defect closure, and septal myomectomy who had complete heart block and had only ventricular pacing leads. The patient had a difficult postoperative course and would have been atrially and ventricularly paced for atrioventricular synchrony. The third and fourth patients were a 24-year-old with tetralogy of Fallot and pulmonary atresia after a right ventricle-pulmonary artery conduit revision and a 17-year-old with severe aortic insufficiency after the Ross procedure. Both patients had a slow junctional rhythm and were hypotensive in the immediate postoperative period and would have undergone atrial pacing. 
TABLE 1. Procedures performed and relationship to pacing

\begin{tabular}{|c|c|c|c|c|}
\hline $\begin{array}{c}\text { Primary procedure } \\
\text { performed }\end{array}$ & All cases $(n=162)$ & $\begin{array}{c}\text { Atrial or ventricular } \\
\text { wires placed }(n=117)\end{array}$ & Paced $(\mathbf{n}=35)$ & $\begin{array}{c}\text { Hemodynamic improvement } \\
\text { with pacing }(n=23)\end{array}$ \\
\hline TOF repair & 20 & 19 & 1 & 1 \\
\hline VSD closure & 19 & 17 & 5 & 4 \\
\hline BDG or hemi-Fontan procedure & 14 & 13 & 5 & 2 \\
\hline Fontan procedure & 10 & 10 & 10 & 6 \\
\hline Arterial switch operation & 10 & 9 & 3 & 1 \\
\hline Norwood or Sano procedure & 8 & 8 & 0 & 0 \\
\hline BT or central shunt & 6 & 2 & 1 & 0 \\
\hline RV-PA conduit replacement & 6 & 6 & 0 & 0 \\
\hline ASD closure & 6 & 1 & 0 & 0 \\
\hline CoA repair & 6 & 0 & 0 & 0 \\
\hline TAPVR repair & 5 & 2 & 2 & 1 \\
\hline PAPVR repair & 5 & 2 & 0 & 0 \\
\hline CAVC repair & 5 & 4 & 1 & 1 \\
\hline Subaortic membrane resection & 5 & 1 & 1 & 1 \\
\hline Ross procedure & 4 & 3 & 0 & 0 \\
\hline PA band & 4 & 2 & 1 & 1 \\
\hline Aortic arch reconstruction & 3 & 3 & 2 & 2 \\
\hline Partial AVC repair & 2 & 1 & 1 & 1 \\
\hline DCRV repair & 2 & 1 & 1 & 1 \\
\hline AP Window repair & 2 & 1 & 1 & 1 \\
\hline Other* & 20 & 12 & 0 & 0 \\
\hline
\end{tabular}

$T O F$, Tetralogy of Fallot; $V S D$, ventricular septal defect; $B D G$, bidirectional Glenn; $B T$, Blalock-Taussig; $R V$, right ventricle; $P A$, pulmonary artery; $A S D$, atrial septal defect; $C o A$, coarctation of the aorta; TAPVR, total anomalous pulmonary venous return; $P A P V R$, partial anomalous pulmonary venous return; $C A V C$, common atrioventricular canal; $A V C$, atrioventricular canal; $D C R V$, double-chamber right ventricle; $A P$, aortopulmonary. *'Other', is defined as mitral valve replacement/repair (n $=3$ ), orthotopic heart transplantation $(\mathrm{n}=3)$, pulmonary artery plasty $(\mathrm{n}=3)$, ventricular assist device placement $(\mathrm{n}=2)$, septal myomectomy $(\mathrm{n}=2)$, repair of anomalous left coronary artery from the pulmonary artery $(\mathrm{n}=2)$, aortopulmonary window repair $(\mathrm{n}=2)$, vascular ring repair $(\mathrm{n}=2)$, Rastelli procedure $(\mathrm{n}=1)$, truncus arteriosus repair $(\mathrm{n}=1)$, and pulmonary valve placement $(\mathrm{n}=1)$.

\section{Predictors}

By using univariate analysis, single ventricle, heterotaxy, the Fontan procedure, use of circulatory arrest, intraoperative arrhythmia, pacing in the operating room, and use of inotropic medications were all predictors for hemodynamic improvement with the use of temporary epicardial pacing wires $(P<.01$, Table 2$)$. Additional variables, such as preoperative arrhythmias, electrocardiographic variables both preoperatively and postoperatively (PR, QRS, and QT intervals and QRS axis), postoperative hemodynamic variables (initial $\mathrm{pH}$, blood pressure, heart rate, and lactate level), and preoperative or postoperative abnormal ventricular function, were assessed and found not to have a statistically significant association with hemodynamic improvement with pacing. On multivariate analysis, the Fontan procedure (odds ratio [OR], 8.6), use of circulatory arrest (OR, 3.1), and intraoperative arrhythmias (OR, 5.7) were independent predictors for hemodynamic improvement with use of temporary epicardial pacing wires (Table 3). When excluding patients from the study group with any of these risk factors $(\mathrm{n}=90)$, only $2(2 \%)$ patients were paced and had significant hemodynamic improvement with pacing. The first patient was a 13-month-old who had been born premature at 28 weeks gestation with single-ventricle physiology who had a slow junctional rhythm postoperatively after the bidirectional Glenn procedure, and the second patient was a 5- year-old with heterotaxy syndrome and subaortic membrane who had a slow junctional rhythm for 48 hours postoperatively. Both patients were atrially paced, and atrioventricular synchrony improved the hemodynamic status.

\section{Outcome}

Outcomes for patients who had hemodynamic improvement with pacing $(n=23)$ were different from those of the rest of the patients $(n=139)$. Patients with clinically significant pacing had spent more time intubated $(3.8 \pm 3.9$ vs $1.6 \pm 1.5$ days, $P<.01)$, had a longer duration of chest tube drainage ( $5.5 \pm 4.4$ vs $3.5 \pm 3.2$ days, $P<.01$ ), had a longer CICU length of stay $(5.5 \pm 3.9$ vs $3.2 \pm 2.8$ days, $P<.01)$, and were more likely to require antiarrhythmic medications $(5 / 23[22 \%]$ vs $4 / 139[3 \%], P<.01)$.

\section{Complications}

There were no complications associated with the use or removal of temporary epicardial pacing wires. All wires were removed by the surgical team before discharge. In 1 patient the pacing wires were inadvertently removed by the patient on postoperative day 1 . An echocardiogram was performed and showed no pericardial effusion, and there were no other complications associated with this inadvertent removal of the pacing wires. There were no arrhythmias noted during 
TABLE 2. Preoperative, operative, and postoperative data

\begin{tabular}{|c|c|c|c|}
\hline & $\begin{array}{l}\text { Not paced or } \\
\text { no improvement } \\
\text { with pacing } \\
(\mathbf{n}=139)\end{array}$ & $\begin{array}{c}\text { Hemodynamic } \\
\text { improvement } \\
\text { with pacing } \\
(\mathbf{n}=\mathbf{2 3})\end{array}$ & $\begin{array}{c}P \\
\text { value }\end{array}$ \\
\hline \multicolumn{4}{|l|}{ Preoperative data } \\
\hline Female sex (n) & $56(40 \%)$ & $11(48 \%)$ & NS \\
\hline Age (y) & $2.4 \pm 4.7$ & $1.5 \pm 1.8$ & NS \\
\hline Weight $(\mathrm{kg})$ & $13.0 \pm 18.0$ & $7.6 \pm 5.0$ & NS \\
\hline Single-ventricle anatomy (n) & $21(15 \%)$ & $9(39 \%)$ & $<.01$ \\
\hline $\begin{array}{l}\text { Complex congenital heart } \\
\text { disease (n) }\end{array}$ & $3(2 \%)$ & $7(30 \%)$ & NS \\
\hline Heterotaxy syndrome (n) & $0(0 \%)$ & $3(13 \%)$ & $<.01$ \\
\hline Trisomy 21 (n) & $12(9 \%)$ & $1(4 \%)$ & NS \\
\hline \multicolumn{4}{|l|}{ Operative data } \\
\hline BPT (min) & $98 \pm 44$ & $106 \pm 48$ & NS \\
\hline CA performed (n) & $37(27 \%)$ & $13(57 \%)$ & $<.01$ \\
\hline $\begin{array}{l}\text { Hemi-Fontan or BDG } \\
\text { procedure }(\mathrm{n})\end{array}$ & $13(11 \%)$ & $2(9 \%)$ & NS \\
\hline Fontan procedure (n) & $4(3 \%)$ & $6(26 \%)$ & $<.01$ \\
\hline Intraoperative arrhythmia (n) & $22(16 \%)$ & $13(57 \%)$ & $<.01$ \\
\hline Paced in OR (n) & $15(11 \%)$ & $11(48 \%)$ & $<.01$ \\
\hline \multicolumn{4}{|l|}{ Postoperative data } \\
\hline Cyanotic (n) & $24(17 \%)$ & $7(30 \%)$ & NS \\
\hline $\begin{array}{l}\text { Antiarrhythmic } \\
\text { medications (n) }\end{array}$ & $4(3 \%)$ & $5(22 \%)$ & $<.01$ \\
\hline Inotropes (n) & $105(76 \%)$ & $22(96 \%)$ & .04 \\
\hline Days intubated & $1.6 \pm 1.5$ & $3.8 \pm 3.9$ & $<.01$ \\
\hline Chest tube drainage (d) & $3.5 \pm 3.2$ & $5.8 \pm 4.4$ & $<.01$ \\
\hline ICU LOS (d) & $3.2 \pm 2.8$ & $5.5 \pm 3.9$ & $<.01$ \\
\hline Hospital LOS (d) & $8.1 \pm 6.3$ & $10.6 \pm 6.0$ & NS \\
\hline $\operatorname{Died}(\mathrm{n})$ & $3(2 \%)$ & $0(0 \%)$ & NS \\
\hline
\end{tabular}

$N S$, Not significant; $B P T$, bypass time; $C A$, circulatory arrest; $B D G$, bidirectional Glenn; $O R$, operating room; $I C U$, intensive care unit; $L O S$, length of stay.

removal of any of the wires, and there were no retained foreign bodies.

During the study period, there were $3(2 \%)$ deaths. All deaths occurred postoperatively, and none were related to arrhythmias or the use of temporary epicardial pacing wires.

\section{DISCUSSION}

Temporary epicardial pacing wires have been used in the postoperative management of heart disease for the past $6 \mathrm{de}$ cades. ${ }^{11-13}$ Weirich and coworkers ${ }^{12}$ reported on the use of temporary pacing in 1957 , and since that time, temporary epicardial pacing wires have been commonly used after repair of congenital heart disease. ${ }^{1-4,14}$ Although temporary epicardial pacing wires are still used commonly after cardiac surgery, there are limited data on the utility, predictors for their use, and complications associated with their use in children.

Recent adult and pediatric literature has indicated that routine placement of temporary epicardial pacing wires is not required during cardiac surgery. ${ }^{5,6}$ The main arguments against the routine placement and use of pacing
TABLE 3. Multivariate analysis model: Significant predictors

\begin{tabular}{lcc}
\hline \multicolumn{1}{c}{ Variable } & Odds ratio & $\boldsymbol{P}$ value \\
\hline Fontan procedure & 8.6 & $<.01$ \\
Use of circulatory arrest & 3.1 & .03 \\
Intraoperative arrhythmias & 5.7 & $<.01$ \\
\hline
\end{tabular}

wires are the risks of complications from their placement, use, and removal. Opponents of the routine placement of temporary epicardial pacing wires argue that the risks associated with the use of wires outweigh the benefits of postoperative pacing. However, we believe that the complication rate from the placement, use, and removal of pacing wires is extremely low and that postoperative pacing can be of significant value in postoperative management. Recently, Fishberger and colleagues ${ }^{6}$ reported that in 1,193 pediatric patients who underwent cardiac surgery over a 3-year period, temporary epicardial pacing wires were placed in only $1.4 \%$ of patients. However, in that series the reported incidence of postoperative arrhythmias was extraordinarily low $(<2 \%)$ compared with rates in the recent literature, which range from $14 \%$ to $29 \%{ }^{2,15-17}$ In addition, in our center junctional ectopic tachycardia is primarily managed with pacing, patient cooling, and weaning exogenous catecholamines, as tolerated. ${ }^{18-20}$ In view of the high incidence of complications in a recent international multicenter study on the use of intravenous amiodarone in pediatric patients, in which adverse events occurred in $87 \%$ of patients, we reserve the use of amiodarone as a second-line therapy when pacing is not feasible or is unsuccessful. ${ }^{21}$

Data on predictors for the use of temporary epicardial pacing wires in the pediatric population are limited. In the adult population Bethea and colleagues 5 found that diabetes mellitus, preoperative arrhythmias, and the need for pacing when separating from cardiopulmonary bypass predicted the need for postoperative pacing. The largest study in children, by Moltedo and associates, ${ }^{2}$ found that patients who had longer cardiopulmonary bypass and aortic crossclamp times were more likely to require pacing. ${ }^{3}$ In that study temporary pacing wires were also frequently used for indications other than pacing because $56 \%$ of patients with wires had the wires used for diagnostic purposes. ${ }^{2}$ In our study, predictors for hemodynamic improvement with postoperative pacing included the occurrence of intraoperative arrhythmias, use of circulatory arrest, and the Fontan procedure. Patients with the presence of any of these risk factors in particular might benefit from the prophylactic placement of temporary epicardial pacing wires. In the absence of the aforementioned risk factors, however, the need for postoperative pacing was very low $(2.2 \%)$.

In our study there were no complications associated with the use of temporary epicardial pacing wires. Similarly, Moltedo and associates ${ }^{2}$ had no complications with the use 
of temporary leads in 170 patients. There are anecdotal case reports of complications associated with the use or removal of temporary pacing wires, such as perforation, tamponade, foreign body retention, migration of the leads, inappropriate atrial or ventricular sensing, and arrhythmias, including ventricular fibrillation. ${ }^{3,7-10}$ The sample sizes of this series and the Moltedo series ${ }^{2}$ are quite small, however, and considering that the risk of complications associated with the use of temporary pacing wires is quite low, we can only argue that the risk of complications with the use of temporary wires is quite small. In our study the benefit of temporary epicardial pacing was notable, with $20 \%$ of the patients having demonstrable clinical improvement. The benefits have greatly outweighed the risks in our population. A limitation of this analysis, however, was that the decision to pace was made by the treating physician. The 12 patients who were paced and did not demonstrate clinical improvement were not included in the analysis, and these patients probably did not need to be paced. In addition, the patients in this series who were paced were likely sicker patients because they required more inotropic support, had a longer duration of intubation and chest tube drainage, and had a longer CICU length of stay.

\section{CONCLUSIONS}

The use of temporary epicardial pacing wires was safe and useful in the management of postoperative arrhythmias after pediatric cardiac surgery. The Fontan procedure, use of circulatory arrest, and the presence of intraoperative arrhythmias were associated with hemodynamic improvement by temporary pacing and might represent indications for empiric placement of pacing wires during surgical intervention. Patients without these risk factors were less likely to require pacing.

\section{References}

1. Del Nido P, Goldman BS. Temporary epicardial pacing after open heart surgery: complications and prevention. J Card Surg. 1989;4:99-103.

2. Moltedo JM, Rosenthal GL, Delaney J, Mello D, Snyder CS. The utility and safety of temporary pacing wires in postoperative patients with congenital heart disease. J Thorac Cardiovasc Surg. 2007;134:515-6.
3. Reade MC. Temporary epicardial pacing after cardiac surgery: a practical review. Part 1: general considerations in the management of epicardial pacing. Anaesthesia. 2007;62:264-71.

4. Yabek SM, Akl BF, Berman W, Neal JF, Dillon T. Use of atrial epicardial electrodes to diagnose and treat postoperative arrhythmias in children. Am J Cardiol. 1980;46:285-9.

5. Bethea BT, Salazar JD, Grega MA, Doty JR, Fitton TP, Alejo DE, et al. Determining the utility of temporary pacing wires after coronary artery bypass surgery. Ann Thorac Surg. 2005;79:104-7.

6. Fishberger SB, Rossi AF, Bolivar JM, Lopez L, Hannan RL, Burke RP. Congenital cardiac surgery without routine placement of wires for temporary pacing. Cardiol Young. 2008;18:96-9.

7. Bolton JW, Mayer JE Jr. Unusual complication of temporary pacing wires in children. Ann Thorac Surg. 1992;54:769-70.

8. Gentry WH, Hassan AA. Complications of retained epicardial pacing wires: an unusual bronchial foreign body. Ann Thorac Surg. 1993;56:1391-3.

9. Imren Y, Zor H, Tasoglu I. Ventricular fibrillation following removal of temporary epicardial pacemaking wires. Cambridge, United Kingdom: Cambridge University Press; 2005.

10. Sugita T, Ando F, Okamoto F, Ikeda T, Ohtani S, Nakanishi K, et al. Unusua complication of temporary pacing wires in children. Ann Thorac Surg. 1993;56: 200-1.

11. Lillehei CW, Sellers RD, Bonnabeau RC, Eliot RS. Chronic postsurgical complete heart block. With particular reference to prognosis, management, and a new P-wave pacemaker. J Thorac Cardiovasc Surg. 1963;46:436-56.

12. Weirich WL, Gott VL, Lillehei CW. The treatment of complete heart block by the combined use of a myocardial electrode and an artificial pacemaker. Surg Forum. 1957;8:360-3.

13. Weirich WL, Paneth M, Gott VL, Lillehei CW. Control of complete heart block by use of an artificial pacemaker and a myocardial electrode. Circ Res. 1958;6:410-5.

14. Takeda M, Furuse A, Kotsuka Y. Use of temporary atrial pacing in management of patients after cardiac surgery. Cardiovasc Surg. 1996;4:623-7.

15. Delaney JW, Moltedo JM, Dziura JD, Kopf GS, Snyder CS. Early postoperative arrhythmias after pediatric cardiac surgery. J Thorac Cardiovasc Surg. 2006;131: 1296-300.

16. Hoffman TM, Wernovsky G, Wieand TS, Cohen MI, Jennings AC, Vetter VL, et al. The incidence of arrhythmias in a pediatric cardiac intensive care unit. $P e$ diatr Cardiol. 2002;23:598-604.

17. Rekawek J, Kansy A, Miszczak-Knecht M, Manowska M, Bieganowska K, Brzezinska-Paszke M, et al. Risk factors for cardiac arrhythmias in children with congenital heart disease after surgical intervention in the early postoperative period. J Thorac Cardiovasc Surg. 2007;133:900-4.

18. Gillette PC. Diagnosis and management of postoperative junctional ectopic tachycardia. Am Heart J. 1989;118:192-4

19. Janousek J, Vojtovic P, Chaloupecky V, Hucin B, Tlaskal T, Kostelka M, et al Hemodynamically optimized temporary cardiac pacing after surgery for congenital heart defects. Pacing Clin Electrophysiol. 2000;23:1250-9.

20. Walsh EP, Saul JP, Sholler GF, Triedman JK, Jonas RA, Mayer JE, et al. Evaluation of a staged treatment protocol for rapid automatic junctional tachycardia after operation for congenital heart disease. J Am Coll Cardiol. 1997;29:1046-53.

21. Saul JP, Scott WA, Brown S, Marantz P, Acevedo V, Etheridge SP, et al. Intravenous amiodarone for incessant tachyarrhythmias in children: a randomized, double-blind, antiarrhythmic drug trial. Circulation. 2005;112:3470-7. 